\title{
IbM PENINGKATAN POTENSI EKOWISATA DI DESA JATIREJO KECAMATAN NGARGOYOSO KABUPATEN KARANGANYAR MELALUI PENGEMBANGAN OLAHAN JAMBU BIJI MERAH SEBAGAI OLEH-OLEH KHAS DESA WISATA JAMBU BIJI MERAH
}

\author{
, Rohula Utami ${ }^{1,2}$, Dwi Ishartani ${ }^{1,2}$, Lia Umi Khasanah ${ }^{1,2}$ \\ ${ }^{1)}$ Pusat Penelitian \& Pengembangan Pangan Gizi dan Kesehatan Masyarakat, LPPM UNS \\ ${ }^{2)}$ Prodi Ilmu dan Teknologi Pangan, Fakultas Pertanian, Universitas Sebelas Maret \\ e-mail : rohulautami@staff.uns.ac.id
}

\begin{abstract}
ABSTRAK
Ekowisata saat ini sedang berkembang pesat. Wisata jenis ini merupakan wisata berwawasan lingkungan yang mengedepankan aspek konservasi alam, pemberdayaan sosial budaya dan ekonomi masyarakat local, serta aspek pembelajaran dan pendidikan. Beberapa pemerintah daerah menangkap peluang ini, di antaranya Kabupaten Karanganyar. Desa Jatirejo Kecamatan Ngargoyoso merupakan salah satu desa di Kabupaten Karanganyar yang dikembangkan sebagai daerah tujuan ekowisata dengan memanfaatkan potensi lokalnya, yaitu budidaya jambu biji merah. Untuk memperkuat citra Desa Jatirejo sebagai Desa Wisata Jambu Biji Merah, maka diperlukan beberapa strategi pengembangan, di antaranya menciptakan oleh-oleh khas Desa Wisata Jambu Biji Merah dengan memanfaatkan potensi lokal. Pada kegiatan IbM ini dilakukan pengembangan olahan jambu biji merah sebagai oleh-oleh khas Desa Wisata Jambu Biji Merah. Mitra yang digandeng pada kegiatan ini adalah UKM Putra Jambu yang saat ini mengolah buah jambu biji merah menjadi es krim dan Kelompok Tani Candi Makmur yang saat ini membudidayakan jambu biji merah serta mengolah daun jambu biji merah menjadi keripik. Kedua UKM memiliki kendala berupa keterbatasan teknologi produksi sehingga menyebabkan mutu produk tidak konsisten, umur simpan pendek, kapasitas produksi rendah dan jangkauan pemasaran sempit, serta keterbatasan pemasaran. Oleh karena itu, pada kegiatan IbM ini dilakukan pendampingan penyusunan Standard Operation Procedure (SOP); introduksi pengemas dan perbaikan labelling pada produk kripik daun jambu biji merah; introduksi peralatan produksi berupa mesin ice cream maker, introduksi otomatic sealer; introduksi peralatan distribusi es krim (freezer), serta pelatihan dan pendampingan pemasaran. Dengan kegiatan ini terjadi peningkatan mutu produk, peningkatan efisiensi kinerja, dan perluasan pasar UKM Putra Jambu dan Kelompok Tani Candi Makmur.
\end{abstract}

Kata kunci : ekowisata, jambu biji merah, Karanganyar, Ngargoyoso, Oleh-oleh 


\begin{abstract}
Ecotourism is currently growing rapidly. This type of tourism is environmentally friendly tourism that promotes the aspects of nature conservation, socio-cultural empowerment, and local community economy, as well as aspects of learning and education. Several local governments seized this opportunity, among them is Karanganyar. Jatirejo Village in Ngargoyoso Subdistrict is one of the villages in Karanganyar which developed as ecotourism destination by exploiting its local potency, that is red guava cultivation. To strengthen the image of Jatirejo Village as the Red Guava Tour Village, it needs several development strategies, among them creating a unique souvenir by utilizing local potency. In this activity is conducted red guava processed development as souvenir typical of Red Guava Tour Village. Partners coupled in this activity is SME (Small Medium Enterprise) Putra Jambu currently processing red guava fruit into ice cream and Kelompok Makmur Candi Tani who currently cultivate the red guava and process the red guava leaves into chips. Both SMEs have constraints in the form of limited production technology, resulting in inconsistent product quality, short shelf life, low production capacity and narrow marketing reach, and limited marketing. The first activities of IbM were accompanied the SMEs to prepare the Standard Operation Procedure (SOP). Introduction of packaging and improvement of labeling on red guava leaf chips also have revealed by this program. Several production equipments also introduced to the SMEs such as ice cream maker machine, automatic sealer, and ice cream distribution equipment (freezer). This program also conducted training and marketing assistance. With this activity, there is an improvement of product quality, performance efficiency improvement, and market expansion of SME Putra Jambu and Farmers Grup Candi Makmur.
\end{abstract}

Keywords: ecotourism, red guava, Karanganyar, Ngargoyoso, Souvenirs. 


\section{PENDAHULUAN}

Kabupaten Karanganyar merupakan salah satu wilayah tujuan wisata unggulan di Jawa Tengah yang saat ini semakin berkembang. Beberapa tempat kunjungan wisata di daerah ini bahkan telah dikenal oleh wisatawan internasional, yang mayoritas berkonsep ekowisata, misalnya Candi Sukuh, Candhi Cetho, perkebunan teh Kemuning dan air terjun Jumog. Ekowisata merupakan wisata berwawasan lingkungan yang mengedepankan aspek konservasi alam, pemberdayaan sosial budaya dan ekonomi masyarakat lokal, serta aspek pembelajaran dan pendidikan. Sejak tahun 2010, ekowisata berbasis cluster juga telah dicanangkan di Kecamatan Ngargoyoso, di antaranya Desa Wisata Jambu Biji Merah di Desa Jatirejo (http://edisicetak.joglosemar.co/berita/ kebun-jambu-ngargoyoso-layak-

dikembangkan-167412.html).

Strategi pencitraan yang tepat diperlukan untuk memperkuat posisi Kecamatan Ngargoyoso sebagai daerah tujuan wisata, khususnya Desa Jatirejo sebagai Desa Wisata Jambu Biji Merah. Selain wisata petik buah jambu biji merah, strategi lain yang dapat ditempuh adalah menciptakan oleholeh khas Desa Wisata Jambu Biji Merah, misalnya olahan jambu biji merah maupun cindera mata. Olahan jambu biji merah berupa es krim jambu biji merah dan keripik daun jambu biji merah saat ini telah mulai dikembangkan di Desa Jatirejo. Kedua produk ini dikembangkan oleh Usaha Kecil Menengah dan Kelompok Tani yang digandeng sebagai mitra IbM ini.

\section{Permasalahan Mitra}

Berikut ini permasalahan yang dihadapi UKM Putra Jambu terkait produksi es krim (velva) jambu biji merah:

1. Mutu produk yang tidak konsisten Mutu produk es krim harus konsisten untuk menjaga kepercayaan konsumen. Mutu produk es krim yang tidak konsisten disebabkan karena proses pengolahan yang tidak konsisten akibat UKM Putra Jambu belum memiliki SOP (Standard 
Operation Procedure) sebagai acuan kerja. Oleh karena itu, proses yang dikerjakan oleh pekerja yang berbeda sering menghasilkan produk es krim dengan mutu yang berbeda.

2. Varian produk yang terbatas UKM Putra Jambu saat ini telah memproduksi es krim jambu biji merah dalam bentuk stick. UKM ingin melakukan diversifikasi produk es krim, yaitu dalam bentuk cup. Namun demikian, UKM masih terkendala masalah peralatan produksi.

3. Jangkauan pasar yang terbatas Untuk mendistribusikan dan mendispaly produk es krim jambu biji merah, diperlukan freezer untuk menjaga mutu produk. Beberapa agen dan ritel mensyaratkan UKM Putra Jambu menyediakan freezer jika ingin berkerja sama dalam penjualan es krim jambu biji merah. Selama ini UKM belum bisa memenuhi persyaratan tersebut sehingga penjualan produk es krim hanya dilakukan di lokasi ekowisata Desa Jambu Biji Merah, belum menjangkau daerah sekitar. Saat ini UKM baru memiliki 2 buah deep freezer yang masing-masing digunakan untuk penyimpanan dan display produk.

4. Ketrampilan yang masih rendah dalam pemasaran produk Dalam pemasaran es krim jambu biji merah, UKM Putra Jambu hanya mengandalkan pemasaran dari mulut ke mulut dan membagikan leaflet kepada wisatawan yang berkunjung ke lokasi ekowisata Desa Wisata Jambu Biji Merah. UKM belum menggunakan media online untuk pemasaran produknya, sehingga pasar atau segmen yang mampu digarap hanya segmen tertentu dan pasar tradisional.

Permasalahan yang dihadapi oleh Kelompok Tani Candi Makmur terkait teknologi produksi keripik daun jambu biji merah adalah : 
1. Kemasan yang tidak menarik dan kurang mampu mempertahankan mutu produk

Kemasan yang digunakan oleh Kelompok Tani Candi Makmur masih berupa plastik PE $0.1 \mathrm{~mm}$ sehingga kurang bisa mempertahankan kerenyahan produk keripik daun jambu biji merah. Akibatnya keripik daun jambu biji merah cepat melempem, tidak ekonomis untuk dipasarkan dan disimpan dalam jangka waktu lama, serta membatasi distribusinya. Selain itu, dengan kemasan plastik polipropilen (PP) $0.1 \mathrm{~mm}$ maka keripik daun jambu biji merah sulit untuk menembus pasar supermarket.

2. Proses pengemasan yang kurang efisien

Pengemasan keripik daun jambu biji merah saat ini dilakukan secara manual. Hal ini menyebabkan proses pengemasan membutuhkan waktu lama dan tenaga kerja yang lebih banyak. Selain itu, factor human eror turut menyebab pengeliman kemasan sering tidak maksimal. Akibatnya, produk mudah rusak (melempem) karena kemasan tidak rapat.

3. Ketrampilan yang masih rendah dalam pemasaran produk Seperti halnya mitra yang satunya, Kelompok Tani Candi Makmur hanya mengandalkan pemasaran dari mulut ke mulut dan membagikan leaflet kepada wisatawan yang berkunjung ke lokasi ekowisata Desa Wisata Jambu Biji Merah untuk memperkenalkan produk keripik daun jambu biji merah. Kelompok tani ini belum menggunakan media online untuk pemasaran produknya sehingga pasar yang mampu digarap hanya segmen tertentu dan pasar tradisional.

\section{METODE}

Metode kegiatan yang akan dilakukan di UKM Putra Jambu adalah sebagai berikut: 
1. Penyusunan Standard Operation Procedure (SOP) Pembuatan Es Krim

SOP akan disusun dengan cara menyelaraskan pengalaman empiris UKM dan pedoman CPPB dari BPOM Depkes RI. SOP yang disusun meliputi SOP penanganan bahan dan SOP proses produksi. SOP ini akan dipasang di ruang produksi yang dimiliki UKM. Untuk menyusun SOP, akan dilakukan pengamatan, pengukuran, dan penetapan parameter mutu, batas kritis, tindakan pengendalian, metode pengujian, dan tindakan koreksi pada setiap tahapan proses, baik penanganan bahan baku maupun proses produksi.

2. Introduksi Alat Ice Cream Maker Alat ice cream maker yang akan diintroduksikan dipilih bersama oleh Tim pengabdian dan UKM mitra. Jumlah ice cream maker yang akan diintroduksikan ada 1 buah.

3. Peningkatan Jangkauan Pasar Untuk menyambut permintaan konsumen (agen) yang menawarkan kerjasama distribusi dengan syarat UKM menyediakan freezer, maka akan diintroduksikan 2 buah freezer.

4. Pelatihan dan Pendampingan Pemasaran

Tim Pengabdian akan mengundang ahli sekaligus praktisi pemasaran untuk memberikan pelatihan pemasaran, khususnya pemasaran online. Oleh karena itu, materi yang diberikan meliputi cara pembuatan website dan media sosial agar UKM dapat mempromosikan produknya melalui media tersebut. Selain itu, UKM akan dilatih bagaimana cara mengelola website dan media social agar informasi selalu dapat diupdate dan mampu merespon konsumen online dengan baik. Setelah pelatihan, tim akan mendampingi UKM dalam memasarkan produksnya.

Metode kegiatan yang akan dilakukan di Kelompok Tani Candi Makmur adalah sebagai berikut:

1. Perbaikan Kemasan

Untuk lebih menarik minat konsumen dan mempertahankan 
mutu produk, akan dilakukan inovasi kemasan baik dari sisi desain, bahan, maupun informasi pada kemasan. Desain kemasan yang akan diintroduksikan dibuat dari plastik PP.

2. Introduksi sealer otomatis

Sealer otomatis diintroduksikan untuk meningkatkan efisiensi dan efektifitas pengemasan.

3. Pelatihan dan Pendampingan Pemasaran

Kelompok tani akan diberi pelatihan sekaligus pendampingan pemasaran online. Kelompok tani akan dilatih tentang cara pembuatan dan pengelolaan media sosial agar dapat mempromosikan produknya melalui media tersebut serta mampu merespon konsumen online dengan baik.

\section{HASIL DAN PEMBAHASAN}

1. Standard Operation Procedure (SOP) Pembuatan Es Krim

SOP pembuatan es krim buah jambu biji merah telah disusun berdasarkan pengalaman empiris dari UKM Putra
Jambu dan disesuaikan dengan pedoman CPPB dari Badan POM RI.

2. Introduksi Alat Ice Cream Maker

Alat ice cream maker yang diintroduksikan ke UKM Putra Jambu memiliki kapasitas 8 liter/jam produksi GEA. Jumlah ice cream maker yang diintroduksikan ada 1 buah. Dokumentasi serah terima es cream maker yang diintroduksikan kepada UKM dapat dilihat pada Gambar 1 .

3. Introduksi freezer

Freezer yang diintroduksikan ke UKM Putra Jambu memiliki kapasitas 250 liter produksi GEA. Jumlah freezer yang diintroduksikan ada 1 buah. Dokumentasi serah terima freezer yang diintroduksikan kepada UKM dapat dilihat pada Gambar 2.

4. Introduksi sealer otomatis Sealer otomatis yang diintroduksikan ke Kelompok Tani Candi Makmur adalah produksi GETRAF dengan model R900V. Jumlah sealer otomatis yang diintroduksikan ada 1 buah. Dokumentasi sealer otomatis yang 
Jurnal SEMAR, ISSN 2302-3937

Vol.6 No.1 Nopember 2017

diintroduksikan kepada UKM dapat

dilihat pada Gambar 3

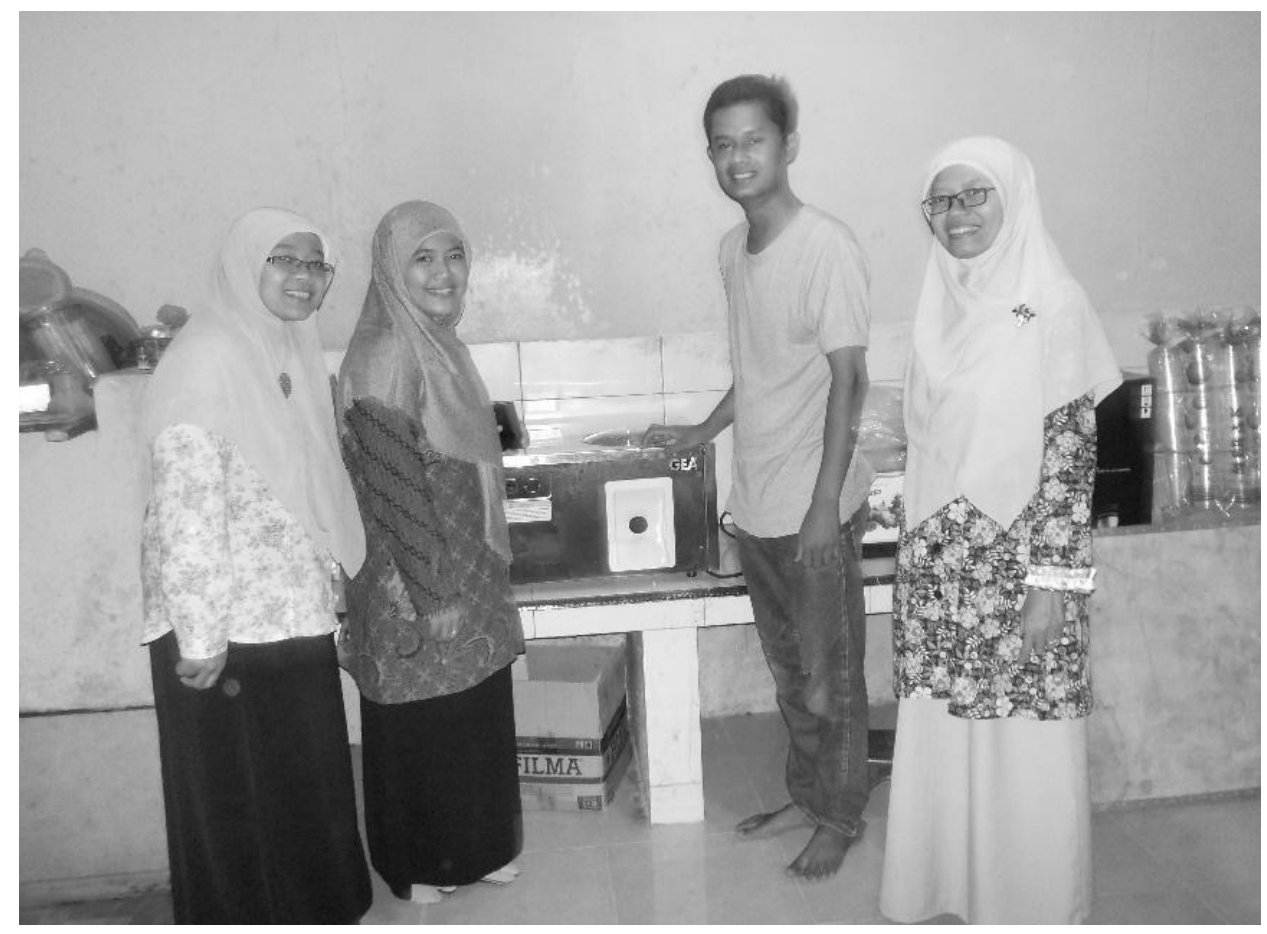

Gambar 1. Serah Terima Ice Cream Maker 


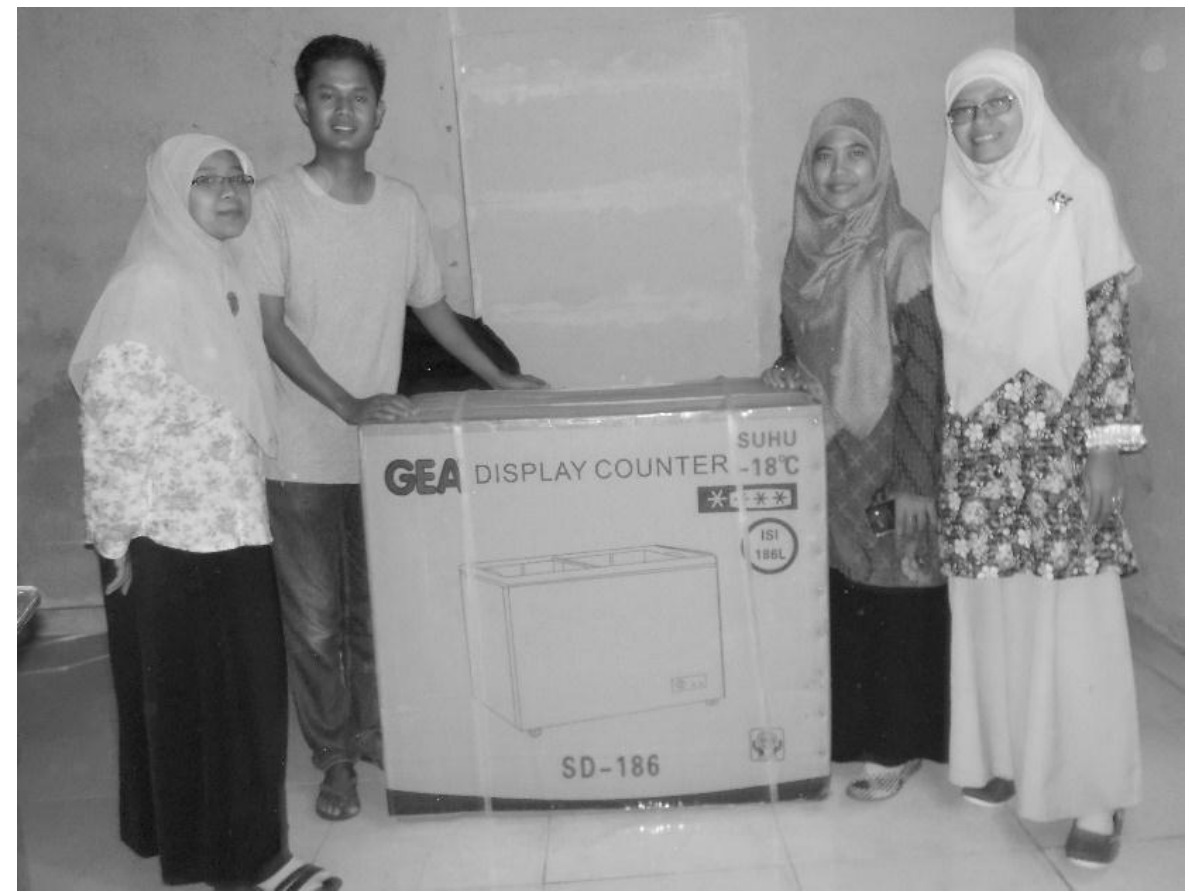

Gambar 2. Serah Terima Freezer.

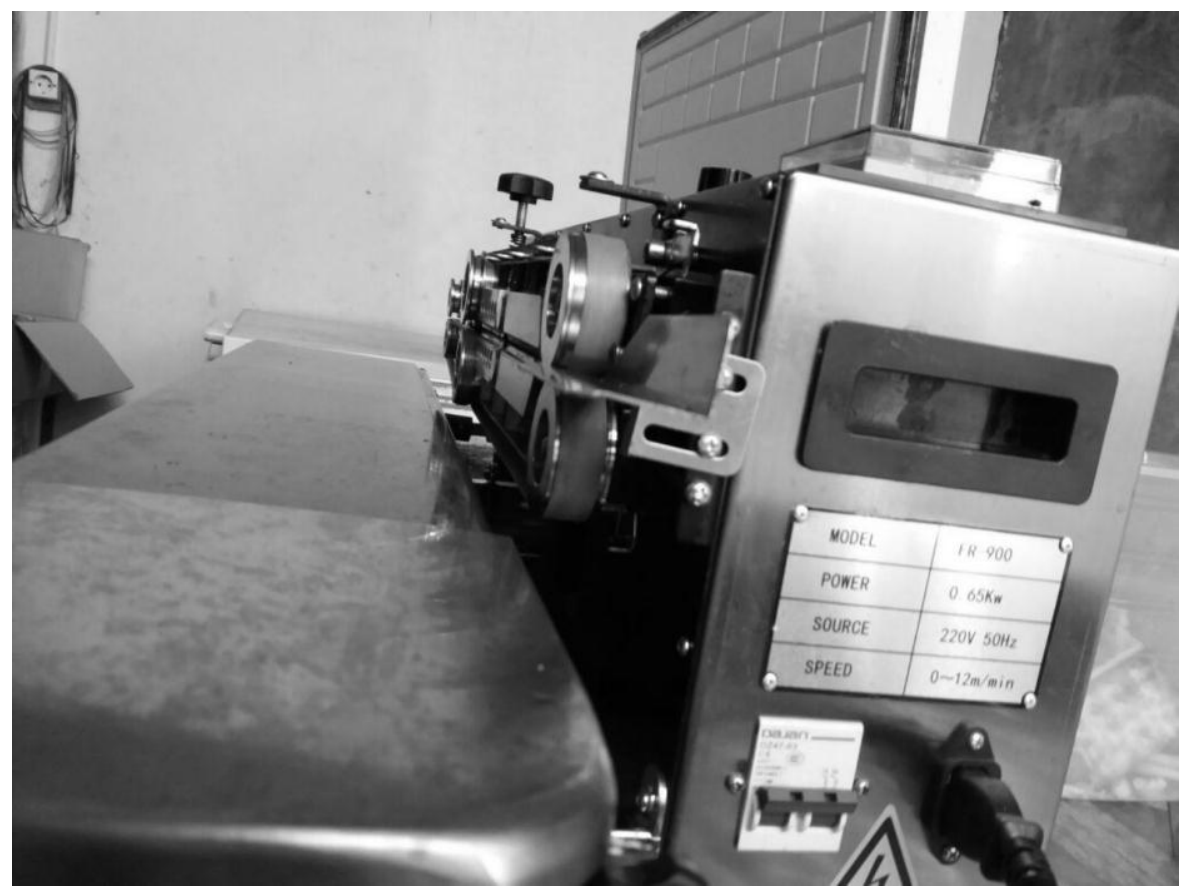

Gambar 3. Sealer kemasan plastik yang diintroduksikan 
5. Perbaikan kemasan dan Label

Kemasan platik PP standing pouch berklip diintroduksikan pada produk keripik daun jambu biji merah. Dengan kemasan ini, produk daun jambu biji merah tampil lebih menarik, praktis, dan mampu bersaing dengan produk oleh-oleh berbasis keripik sayuran daun lainnya. Introduksi label yang menarik dan informatif juga semakin memperkuat identitas produk, menjamin perlindungan konsumen, serta sekaligus menjadi media promosi bagi Kelompok Tani Candi Makmur. Gambar produk keripik daun jambu biji merah dengan kemasan dan label baru hasil introduksi kegiatan IbM ini dapat dilihat pada Gambar 4.
6. Pelatihan dan Pendampingan

Pemasaran

Pelatihan pemasaran dilakukan bagi kedua mitra. Masing-masing dua orang perwakilan UKM Putra Jambu dan Kelompok Tani Candi Makmur dikirimkan mengikuti kegiatan Gebyar UKM Indonesia 2017 yang diadakan oleh Mark Plus Inc. di bawah pimpinan ahli pemasaran Bapak Hermawan Kertajaya. Kegiatan Gebyar UKM Indonesia berisikan materi pemasaran umum, pemasaran online, dan pameran produk UKM. Dengan mengikuti pelatihan ini, mitra semakin pahan teknik-teknik pemasaran, termasuk pemasaran online, serta memperluas jaringan pemasaran. 


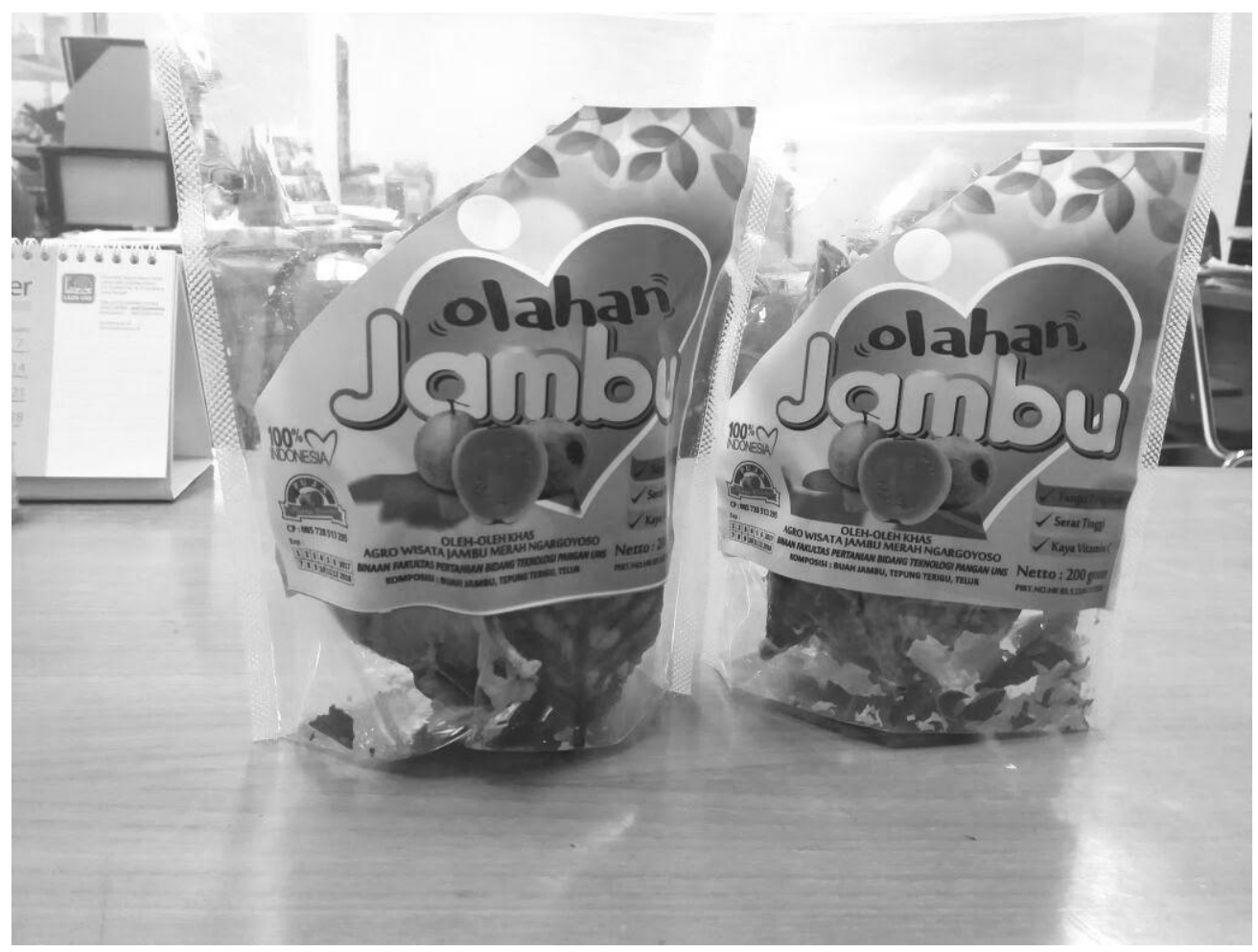

Gambar 4. Kemasan standing pouch berklip dan label yang diintroduksikan 


\section{PENUTUP}

Hasil kegiatan IbM ini menjawab permasalahan yang dihadapi mitra yaitu terjadi peningkatan mutu produk, peningkatan efisiensi kinerja, dan perluasan pasar UKM Putra Jambu dan Kelompok Tani Candi Makmur. Kedua mitra masih memerlukan pendampingan, diantaranya dalam melakukan difersifikasi produk, manajemen dan perluasan pasar. Selain itu, pendampingan serupa dengan kegiatan IbM ini masih diperlukan bagi kelompok-kelompok tani di cluster Desa Wisata Jambu Biji Merah Ngargoyoso.

\section{UCAPAN TERIMA KASIH}

Kegiatan IbM ini terselenggara atas pembiayaan dari Direktorat Riset dan Pengabdian Masyarakat Direktoral Jenderal Penguatan Riset dan Pengembangan Kementerian Riset, Teknologi, dan Pendidikan Tinggi sesuai dengan Perjanjian Penugasan

Pelaksanaan Program Pengabdian Masyarakat Nomor : 028/SP2H/PPM/DRPM/IV/2017, tanggal 3 April 2017.

\section{REFERENSI}

http://edisicetak.joglosemar.co/berita/k ebun-jambu-ngargoyoso-layakdikembangkan-167412.html. Diunduh 15 Februari 2016 


\section{BIODATA PENELITI}

\section{Rohula Utami STP, M.P.}

Tenaga pendidikan atau desen di program studi IImu dan Teknologi Pangan Fakultas Pertanian Universitas Sebelas Maret Surakarta. Dilahirkan di Sragen pada 6 Maret 1981. Pengabdian yang pernah dilakukan adalah IbM Peningkatan Potensi Ekowisata di Desa Jatirejo Kecamatan Ngargoyoso Kabupaten Karanganyar Melalui Pengembangan Olahan Jambu Biji Merah Sebagai Oleh-Oleh Khas Desa Wisata Jambu Biji Merah. 